\title{
DESIGUALDADE E LIMITES DO GOVERNO DAS LEIS
}

\author{
Oscar Vilhena Vieira \\ Professor da Faculdade de Direito da PUC-SP, Secretário Executivo do Instituto Latino-Americano das Nações Unidas para \\ Prevenção do Delito e Tratamento do Delinqüente no Brasil
}

$\mathrm{H}$ á hoje uma forte percepção, decorrente do aumento da criminalidade ${ }^{1}$ e das reiteradas violações de direitos humanos, de que a lei não tem se demonstrado um instrumento capaz de conter a irracionalidade e o arbítrio, estatal ou individual, em nossa sociedade, enfim, de que embora tenhamos deixado o regime de exceção e constituído um estado de direito, ao menos a partir da Constituição de 1988, o respeito ao direito é ainda limitado (O'Donnell, 1998:37), o que justifica a dúvida sobre estarmos ou não vivendo num autêntico estado de direito.

A expressão estado de direito tem sido um poderoso instrumento no processo de derrubada de regimes autoritários nas últimas décadas. ${ }^{2}$ Assim como democracia e mercado (notadamente nos últimos anos), a expressão incorporou-se ao vocabulário das grandes transformações ocorridas na América Latina, nos anos 70 e 80, e no leste europeu, do final dos anos 80 até o presente. Nestas batalhas, o termo estado de direito tem sido predominantemente usado como uma contraposição ao emprego arbitrário do poder e uma aspiração ao bom governo. Muito embora a utilização do conceito de estado de direito seja algumas vezes confusa, não é totalmente arbitrária, uma vez que se baseia no ideal de que o governo das leis, fundado na razão e liberdade, é superior ao governo dos ditadores, das juntas, do partido único, ou outras formas opressivas de exercício do poder. Mas se este conceito é um bom slogan na desconstrução de antigos regimes, é muito abstrato no momento da construção e implementação de uma nova ordem legal. E como o fim do regime autoritário não significa o começo automático do gover- no das leis, é necessário compreender o que significa exatamente estado de direito e como pode ele auxiliar na construção de regimes menos opressivos e que se estendam a todos os setores da sociedade.

Na literatura política contemporânea, o ressurgimento do conceito de estado de direito está diretamente ligado aos trabalhos de F. A. Hayek, não coincidentemente um dos principais teóricos do estado mínimo, do neoliberalismo. Para esse autor, estado de direito e mercado estão diretamente relacionados e dependentes. $\mathrm{O}$ estado de direito é a melhor forma de se assegurar as liberdades necessárias ao funcionamento do mercado, e este, por sua vez, é o ambiente econômico próprio para a realização do estado de direito. Para Hayek, toda forma de intervenção redistributivista ou regulamentação da economia põe em risco o estado de direito, pois subverte seus elementos formais, como generalidade e abstração das leis, e só pode ser colocada em prática a partir de uma supressão das liberdades negativas.

A hipótese deste trabalho, no entanto, é que o essencial para a construção de um estado de direito é a existência de uma sociedade formada a partir de relações voluntárias e recíprocas, o que propicia a generalização de expectativas de cumprimento das obrigações. Para que isto aconteça, é necessário haver um equilíbrio de recursos ${ }^{3}$ entre os diversos membros desta sociedade e, portanto, um mínimo de igualdade social. Isto certamente não exclui o mercado, mas apela para a sua correção, principalmente no que se refere à distribuição de riquezas por ele gerenciadas.

O objetivo deste artigo é analisar a situação do estado de direito no Brasil à luz das discussões teóricas acerca 
do que se compreende por esta expressão nos dias de hoje. Na primeira etapa, serão exploradas algumas concepções, com especial atenção às questões de igualdade, reciprocidade, congruência e também ao problema do monopólio público dos meios de coerção (Weber), que vemos como um dos principais problemas do sistema legal brasileiro. Na segunda parte, será feita uma rápida apresentação do sistema legal brasileiro, sob a ótica dos ideais de estado de direito analisados na primeira parte do trabalho. Nossa hipótese é que a falta de congruência entre o direito escrito nos "códigos" e o comportamento dos agentes do Estado (de policiais militares a magistrados), que se verifica no sistema jurídico brasileiro, é, entre outros fatores, consequiência de altos níveis de desigualdade social e econômica, que danificam o tecido social, rompendo as relações de reciprocidade essenciais a uma administração coerente do direito. Neste sentido, acatamos a proposição de Fuller (1969), segundo a qual reciprocidade é um elemento crucial à existência de um estado de direito, mas questionamos que o mercado, por si só, crie um ambiente propício ao surgimento de relações pautadas pela igualdade e reciprocidade, ou seja, onde as obrigações e direitos de indivíduos e agentes do Estado sejam mutuamente reconhecidos.

\section{O CONCEITO DE ESTADO DE DIREITO}

\section{Monopólio Público dos Meios de Coerção, uma Precondição}

Em um clássico da literatura constitucional do início do século, A. V. Dicey destacava que dois são os aspectos que caracterizam as instituições inglesas: em primeiro lugar a "onipotência ou indisputada supremacia do governo central em todo o país..." (Dicey, 1982:107), e em segundo, a existência do rule of law. Seguindo os autores clássicos de Hobbes a Weber, assume-se neste trabalho que a centralização e monopólio dos meios coercitivos é uma precondição da existência do estado de direito. Mesmo aqueles que não vêem a lei como um mero fato de poder - como Hobbes e os demais positivistas, para quem auctoritas non veritas facit legem -, mas como uma empreitada normativa e inter-relacional (Fuller, 1969:221), consideram a presença de autoridades, de uma terceira parte responsável por aplicar o direito, como sempre necessária. Isto reafirma a necessidade de um Estado e de sua luta pelo monopólio dos meios de coerção no processo de pacificação da sociedade - para usar a terminologia de Norbert Elias (1993). O fato é que em muitas das novas democracias não existe um autêntico monopólio "público" dos meios de coerção, o que gera uma fragilidade do Estado na aplicação do direito; e o termo "público" e não "estatal" está sendo utilizado para possibilitar a seguinte diferenciação: em muitos sistemas, embora o Estado controle considerável quantidade dos meios de coerção, estes meios não são utilizados com finalidade pública. Porém, são colonizados por indivíduos privados ou grupos, no que Weber denomina Estado patrimonial, para assegurar privilégios e relações assimétricas dentro da sociedade. Em outras situações, os Estados são simplesmente frágeis, incapazes de superar outros grupos armados em seus territórios.

Muito embora esse processo de monopolização dos meios de coerção pareça crucial na constituição de uma sociedade pacificada, onde a integridade física (e alguma dose de autonomia) não esteja em constante ameaça diante dos demais membros da sociedade, a atribuição desse poder ao Estado constitui uma ameaça em si mesma. Aqui é que o estado de direito se demonstra mais importante, como instrumento de controle e domesticação do Leviatã.

\section{Em Busca de uma Concepção Substantiva de Estado de Direito}

Os conceitos anglo-americano de Rule of Law e germânico de Rechtsstaat dos séculos XVIII e XIX, que passaram por uma longa crise prevista por Max Weber, têm sido objeto de importantes reformulações teóricas neste último século. Em Economia e sociedade, escrito no início deste século, Weber alertava para o processo de desformalização do direito como conseqüência de transformações na esfera pública (Weber, 1984:648 e ss.). As décadas que se seguiram a esse trabalho foram marcadas por um intenso debate intelectual e político a respeito da capacidade do Rechtsstaat de enfrentar os desafios impostos pela Constituição social-democrata de Weimar, opondo conservadores como Carl Schmitt e social-democratas como Franz Neumann e Herman Heller. No mundo acadêmico anglo-americano, o economista austríaco Friedrich Hayek foi responsável pela mais importante reformulação e a defesa mais substantiva do estado de direito como instrumento de proteção da liberdade dos indivíduos contra o constante aumento da intervenção do Estado na esfera econômica (Hayek, 1944 e 1960). ${ }^{4}$

Para Hayek, a intervenção do Estado na economia e o crescimento do poder discricionário dos burocratas para 
estabelecer e implementar metas sociais ameaçam diretamente a liberdade; ao mesmo tempo, e como conseqüência destas transformações nas funções do Estado, houve um declínio do direito como um instrumento substantivo de proteção da liberdade. A noção de que o Estado tinha a obrigação não apenas de tratar seus cidadãos como iguais perante a lei, mas também de assegurar uma justiça substantiva, foi acompanhada pelo argumento dos novos teóricos do direito de que o conceito clássico de estado de direito era incompatível com a nova realidade econômica e política. Diferentes perspectivas teóricas, como positivistas, realistas, escola livre de direito, jurisprudência de interesses colaboraram ainda que antagonicamente para a construção de um conceito dessubstancializado do direito, libertando assim o Estado das limitações impostas pela noção substantiva de lei (Hayek, 1960:cap. XVI).

Para superar esta situação de opressão, em que o Estado pode coagir seus cidadãos, através de atos normativos, sem a necessidade de justificá-los em uma lei geral e abstrata, é necessário, para Hayek, retornar ao antigo conceito de estado de direito. Com este propósito, ele revisita a história do conceito e estabelece uma lista de elementos normativos essenciais do estado de direito como um instrumento que, por excelência, assegura a liberdade. Por ser uma concepção substantiva, "concernente com o que a lei deve ser, um doutrina meta legal e um ideal político" (Hayek, 1960:206), e não uma mera concepção de governo agindo por intermédio de atos normativos expedidos pelo Legislativo ou pelo Executivo para a realização de seus objetivos, o estado de direito não poder ser equiparado ao princípio da legalidade desenvolvido pelo direito administrativo. O estado de direito, para Hayek, teria de ser estruturado pelos seguintes elementos: a) a lei deveria ser geral, abstrata e prospectiva, de modo que o legislador não pudesse escolher uma pessoa ou grupo que fosse alvo de sua coerção ou privilégio; b) a lei deveria ser conhecida e certa (estável), para que as pessoas pudessem planejar (este foi, segundo ele, um dos fatores decisivos para a prosperidade do ocidente); c) a lei deveria ser aplicada de forma igual para todos, cidadãos e autoridades, o que reduziria a quantidade de leis injustas; d) deveria haver uma divisão entre legisladores e aplicadores do direito, juízes e administradores, evitando assim que as leis fossem feitas para a solução de casos particulares; e) deveria existir um controle judicial dos atos discricionários da administração para corrigir a má aplicação da lei; f) legislação e políticas (públicas) também deveriam ser separadas, e a utilização da coerção estatal justificada apenas por meio de lei, para prevenir a coerção discriminatória de indivíduos; g) deveria haver uma carta de direitos não exaustiva para proteger a esfera privada. Assim, a concepção hayekiana de estado de direito tem o propósito claro de estruturar o sistema de mercado, através de um conceito substantivo de lei, ${ }^{5}$ a existência de direitos individuais e a separação de poderes. Trata-se de um modelo normativo, que propõe a melhor fórmula de se alcançar a liberdade (como ausência de obstáculo), preconcebida para o bom funcionamento do mercado. As idéias de Hayek no campo constitucional e legal são, no entanto, extremamente relevantes. Elas recuperam a dignidade do conceito de lei, perdida no período do estado regulador, visto que esta constitui um "invento" essencial no processo de civilização da sociedade e domesticação do Estado. O modelo de Hayek, embora tenha despertado para a necessidade de se reformular normativamente o conceito de estado de direito, que se deteriorou em razão do formalismo e do relativismo de diversas correntes, com efeitos catastróficos em algumas sociedades, não nos ajuda a pensar a dinâmica pela qual o estado de direito é possível. Daí ser extremamente interessante conhecer o tratamento dispensado por Lon Fuller a este tema.

\section{Reciprocidade e Estado de Direito}

Entre os diversos objetivos que Fuller persegue em seu livro The morality of law, o estabelecimento de um conceito de estado de direito que possa ser utilizado como escala para medir a qualidade intrínseca dos sistemas jurídicos parece ser o mais interessante. ${ }^{7}$ Fuller busca criar uma versão paradigmática de estado de direito como instrumento cognitivo, distinto de parâmetros substantivos de justiça e de noções de direito natural, ${ }^{8}$ para servir como padrão de avaliação dos sistemas jurídicos (Fuller, 1969: 146-7). Na sua visão, a perspectiva positivista que entende a lei como um fato de autoridade, e não como um empreendimento propositivo moral, perde qualquer capacidade normativa para checar o cumprimento do ideal de legalidade pelo sistema jurídico. O mais interessante de sua análise, entretanto, é que Fuller deriva seu modelo normativo de uma série de condições sociais. Neste sentido, indica quais são os elementos para a construção de um estado de direito.

Para ele, o modesto propósito dos sistemas legais é submeter "a conduta humana a orientação e controle de regras gerais" (Fuller, 1969:146). Para alcançar este pro- 
pósito, os sistemas legais deveriam incorporar uma série de elementos, ou "excelências", que constituiriam a "moralidade interna do direito". A primeira destas excelências é a própria existência de regras. Estas também devem ser públicas, prospectivas, não contraditórias entre si, compreensíveis e estáveis para que as pessoas possam se pautar por elas. A última excelência que compõe a moralidade interna do direito é a congruência entre as regras e sua efetiva administração e aplicação. São estas, portanto, as oito "excelências" que compõem a essência do estado de direito (Fuller, 1969:39).

A enumeração de Fuller, embora semelhante em diversos pontos aos elementos da formulação proposta por Hayek, é mais modesta e procedimental; não exige uma carta de direitos ou uma clara separação de poderes, com um Poder Judiciário independente. ${ }^{9}$ Além desta diferença, o método adotado por Fuller para chegar a sua formulação também é distinto e, certamente, mais frutífero. Ele inicia seu livro distinguindo a moralidade do dever da moralidade de aspiração. A moralidade do dever "estabelece regras básicas sem as quais uma sociedade organizada seria impossível". É um tipo de moralidade fundada no Antigo Testamento ("não deves"), enquanto a moralidade de aspiração é uma moralidade da boa vida. A moralidade do dever pode ser comparada com as regras da gramática e a moralidade da aspiração, com as regras da boa composição. Na escala moral, a moralidade do dever está embaixo e a moralidade de aspiração, no topo. A difícil questão é estabelecer uma linha divisória entre o que é dever e o que é apenas uma questão de melhora da vida humana.

O direito e os deveres legalmente estabelecidos são primos irmãos da moralidade de dever. O sistema legal, no entanto, tem o propósito de "reduzir o papel do irracional nos afazeres humanos" e, nesse sentido, está mais próximo de uma moralidade de aspiração. Uma outra analogia feita pelo autor, que é importante para a compreensão de sua principal hipótese, é a relação entre moralidade de dever e economia de mercado. Um grande número de deveres decorre de relações de troca, promessas e contratos, o que não significa, no entanto, que toda obrigação decorra de uma transação. Em muitas ocasiões é apropriado dizer que alguém tem um dever que não deriva de uma relação contratual, como a obrigação de votar. Esse dever deriva, na linguagem de Fuller, de uma relação de reciprocidade, de uma expectativa de que outros também realizem certos atos que darão significado e sentido ao seu voto. No mesmo sentido, os deveres não decorrem apenas de relações de troca, mas de situações em que existe uma colaboração anônima ou em outras situações de autoimposição. Assim, Fuller propõe que as sociedades regidas pelas leis do mercado não se compõem apenas de uma rede de barganhas, mas também de uma anônima e constante colaboração entre os seus membros. Colaboração que se canaliza "através das instituições e procedimentos de uma sociedade organizada" (Fuller, 1969:22).

Esta noção de reciprocidade pode ser representada pela seguinte regra de ouro: "Assim que se torne perfeitamente claro que você não tem intenção de me tratar como gostaria de ser tratado, eu me considero livre da obrigação de tratá-lo como eu gostaria de ser tratado" (Fuller, 1969:21). Assim, o que mantém a sociedade unida, além das obrigações derivadas dos contratos, são as obrigações derivadas de expectativas mútuas expressas por relações de reciprocidade (Fuller, 1969:23).

Fuller vê as sociedades de troca como ambientes propícios para a realização da moralidade interna do direito. Apenas nessas sociedades pode alguém achar as "três condições ótimas para a eficácia da noção de dever": a voluntariedade, de ambas as partes, com que a relação de reciprocidade, da qual a obrigação deriva, se constitui; a igualdade entre as obrigações a serem prestadas pelas partes, que só podem ser estabelecidas pelo mercado; e a reversibilidade, ou seja, que a sua posição nas relações contratuais não seja sempre a mesma, pois a todo o tempo se pode trocar de posição com a outra parte. Estes elementos facilitam enormemente o cumprimento sem necessidade de coerção dos deveres de cada uma das partes e, portanto, da realização do estado de direito.

O que faz a análise do estado de direito realizada por Fuller mais atrativa do que a abordagem sociológica de Weber ou a normativa proposta por Hayek é, em primeiro lugar, a capacidade do autor de retirar de uma sociedade regida pelo mercado uma formulação normativa do estado de direito que, embora rejeitando as formulações tradicionais do direito natural como lei superior, é capaz de oferecer um instrumento normativo crítico para medir a integridade dos sistemas jurídicos. Em segundo lugar, a idéia de reciprocidade dá um caráter dinâmico a sua formulação, rejeitando a idéia positivista de que a lei vige onde há autoridade para impô-la, e desmistificando em alguma medida o conceito de legitimidade, muitas vezes utilizado para justificar a maior ou menor eficácia do direito. Assim, o direito alcança eficácia não apenas quando é fruto da vontade consensual dos cidadãos, mas quando a disponibilidade de respeitar aquele direito é mutuamente 
esperada. Tautologicamente falando, é a realização das expectativas da efetivação do direito que aumenta a sua eficácia. Trata-se, assim, de um processo construtivo. Neste sentido, as sete primeiras excelências da "moralidade interna" do direito, que constituem o conceito de estado de direito de Fuller, só podem ter sucesso a partir da existência de uma vasta rede de relações de reciprocidade, entendida como conjunto de colaborações autônomas, associadas a obrigações mutuamente aceitas por via contratual, e o senso de dever moral entre indivíduos e agentes estatais.

\section{Congruência e Estado de Direito}

A principal crítica às duas formulações de estado de direito que acabamos de analisar é que elas são ideologicamente vinculadas à proteção do sistema de mercado. No que se refere especificamente a formulação de Hayek, a crítica é ainda mais aguda, pois trata-se de uma concepção meramente normativa, fundada em um conceito de bem viver inerente às sociedades de mercado, sendo portanto totalmente impotentes para analisar uma sociedade que não adote como regra fundamental a ampla liberdade do mercado. Na verdade, a representação mais radical deste argumento antecede as obras de Hayek e Fuller, tendo expressamente influenciado a do segundo, e foi formulada por um jurista marxista. Para Passukanis, fora do mercado não existe direito, pois este deriva única e exclusivamente das relações de troca. "O poder político pode, com a ajuda das leis, regular, modificar, determinar, concretizar do modo mais diverso a forma e o conteúdo deste contrato jurídico... A jurisprudência dogmática conclui daí que todos os elementos existentes da relação jurídica, inclusive também o próprio sujeito, são gerados pela norma. Na realidade, a existência de uma economia mercantil e monetária é, naturalmente, a condição fundamental, sem a qual todas estas normas concretas carecem de qualquer sentido... Aí onde falte este substrato (mercado), é a priori inconcebível a relação jurídica correspondente" (Passukanis, 1977:106-107). Assim, sociedades socialistas podem possuir outras fórmulas para coordenação de seus indivíduos, que não se confundem com a idéia de indivíduos dotados de direitos subjetivos.

Ao lado destas formulações, tanto liberais como marxistas, que só vêem como possível a existência de um estado de direito em relação direta com uma economia de troca, há formulações que, levando em conta alguns dos principais elementos normativos das concepções de Hayek e Fuller, mantêm-se mais neutras em relação ao papel que o Estado desempenha na economia. Exemplo disso é a concepção de estado de direito formulada por Joseph Raz. Para este autor, o estado de direito em sentido amplo significa que as pessoas deveriam obedecer o direito e serem governadas pelo mesmo, e, em um sentido mais restrito, político e jurídico, que o governo deve reger-se pelo direito e a ele estar submetido (Raz, 1979:4). A questão: o que se concebe por direito? Se alguém entende por direito pura e simplesmente aquilo produzido conforme as regras de reconhecimento de Hart (1972:111), ou a norma hipotética fundamental de Kelsen (1972:267), o estado de direito será um conceito vazio. Para dar alguma consistência ao conceito de estado de direito, a construção de Raz exige que a lei seja compreendida como regra geral e abstrata, para que efetivamente possa guiar as ações, compatibilizando-se assim com as formulações de Hayek e Fuller. Assim, o direito não requer certa substância específica, mas deve ter uma forma particular. Raz, no entanto, discorda dos autores analisados no sentido de que para ele a constituição de um estado de direito não exige apenas regras gerais e abstratas. Para Raz, seria impossível governar apenas a partir de regras gerais; qualquer sistema concreto deve ser composto por regras gerais e particulares, sendo que as particulares devem estar em conformidade com as gerais (Raz, 1979:6). Para cumprir o objetivo dos sistemas jurídicos de guiar as ações individuais, ele compõe da seguinte forma o seu estado de direito: as regras devem ser prospectivas, claras, relativamente estáveis e a feitura das regras particulares deve guiar-se por leis com as características mencionadas. Mas estas leis só farão sentido se devidamente aplicadas por instituições responsáveis. Apenas assim, a lei se tornará um efetivo guia para as ações individuais. E este é o quarto elemento no conceito de estado de direito formulado por Raz. Este modelo exige um Judiciário independente, pois sendo as normas razões para ações, seria "fútil alguém guiar suas ações com base na lei se quando a questão tiver que ser adjudicada os tribunais não aplicarem a lei..." (Raz, 1979:10). Pela mesma razão, o princípio da justiça natural ${ }^{10}$ deve ser obedecido, os tribunais devem poder rever atos dos outros órgão do poder. O acesso aos tribunais deve ser amplo para não se frustrar o estado de direito. Por último, os poderes discricionários das agências de prevenção da criminalidade devem ser limitados para que não pervertam a aplicação da lei. Neste sentido, nem o ministério público nem a polícia devem ter discricionariedade para alocar os seus recursos no combate à criminalidade, senão com base no estabelecido pela lei. 
Concentrar atenções nas agências e agentes de aplicação do direito coincide com o entendimento de Fuller de que a questão da congruência é a mais complexa no que diz respeito à moralidade interna do direito. Além do mais, essa reflexão traz sangue novo ao debate sobre o estado de direito no momento em que a grande maioria das novas democracias está em conformidade com as demais "excelências" do estado de direito, comumente exigidas pelos autores em tela, sem, no entanto, atingir um autêntico estado de direito. ${ }^{10}$ Mantendo estes modelos em mente, buscaremos demonstrar que o sistema legal brasileiro, muito embora em conformidade com a maior parte dos elementos que fazem de um sistema legal um estado de direito, não atinge a "excelência da congruência". Nossa hipótese e principal objeção à teoria de Fuller, no entanto, é que a economia de mercado por si não oferece todas as condições para o desenvolvimento do estado de direito. A partir do caso brasileiro buscaremos demonstrar que um mínimo de igualdade econômica e social ${ }^{12}$ é crucial para o estabelecimento de relações de reciprocidade e, portanto, para a existência de um estado de direito.

\section{O ESTADO DE DIREITO NO BRASIL}

\section{Aspectos Formais}

O Brasil passou por um dos mais longos processos de transição de que se tem lembrança. Em 1974, o então presidente, general Ernesto Geisel, "comprometeu seu governo a iniciar um processo de abertura política" (Huntington, 1991:5). Eleição para os corpos legislativos nunca foram totalmente proibidas durante o regime militar, muito embora o sistema político fosse limitado pela eliminação de partidos e políticos não desejados, restrição a direitos civis e políticos e à liberdade de expressão e, o mais grave, tortura e desaparecimentos políticos. O Judiciário foi proibido de revisar ações fundadas nos atos institucionais, que eram os principais veículos normativos voltados a ultrapassar os obstáculos criados pelas Constituições que vigoraram no período. Em 1979, uma lei de anistia foi aprovada permitindo que dissidentes políticos voltassem ao país e libertando aqueles que ainda continuavam encarcerados. Depois de 1980, atos limitando a organização política e sindical e os direitos civis e políticos foram suspensos. Nos anos 80, eleições foram realizadas para todos os níveis da administração, inclusive para a presidência da República. O processo de transição teve seu apogeu com a elaboração, em 1988, de uma nova Consti- tuição compromissada com os valores do estado de direito e dos direitos humanos.

A nova Constituição incorpora uma completa lista de direitos, mais extensa que a da Carta Internacional de Direitos Humanos, que inclui direito civis, políticos, sociais e econômicos, assim como protege direitos de grupos específicos, como índios, crianças e idosos. O Brasil é hoje parte nos principais tratados internacionais de proteção da pessoa humana, que, por força do parágrafo $2^{\circ}$ do art. 5ํ da Constituição, têm eficácia imediata no sistema jurídico brasileiro. A lei é, em princípio, o único instrumento que pode impor obrigações aos indivíduos, sendo considerados lei aqueles atos emanados dos poderes legislativos, processual e substantivamente de acordo com a Constituição; todas as pessoas são consideradas iguais perante a lei (caput do art. 5ㅇ); as leis não podem retroagir, salvo para benefício do indivíduo (art. 5o, XL).

Os maiores entraves à realização do princípio da legalidade no Brasil são a existência e o uso descontrolado de medidas provisórias pelo Executivo federal. Embora estas só pudessem ser editadas em caso de "relevância e urgência" (art. 62), as medidas provisórias se tornaram o principal mecanismo legislativo do governo. A prática de reeditar medidas provisórias que não são apreciadas pelo Congresso Nacional, no prazo de um mês, dá ao Executivo uma capacidade de legislar incompatível com os princípios da separação de poderes e da democracia. Mais do que isto, cria um modelo de norma jurídica mutante, que mensalmente sofre alterações, o que provoca uma erosão do próprio cerne da idéia de lei enquanto instrumento com pretensão de perenidade.

Em resumo, as medidas provisórias não se adequam a qualquer das definições de estado de direito aqui analisadas. No que se refere aos demais elementos do nosso ordenamento jurídico, poder-se-ia dizer o seguinte: embora muitas das leis brasileiras jamais pudessem passar no teste de generalidade exigido pela formulação de Hayek, visto que muitas delas têm destinatários específicos, como leis editadas em qualquer sociedade pós-liberal, elas certamente seriam aprovadas pelo modelo descrito por Raz, no qual as leis específicas têm legitimidade se compatíveis com as genéricas. Também pensamos que, em sua maioria, as leis brasileiras não são mais incompreensíveis do que as de outros países considerados estados de direito. Assim, muito embora o sistema legal brasileiro não seja compatível com algumas exigências do modelo de estado de direito de Hayek, principalmente devido às questões econômicas ligadas à generalidade e à abstra- 
ção da lei, seria mais aceitável pela formulação de Fuller e certamente compatível com o modelo de Raz. Isto, lembre-se bem, em relação às primeiras sete excelências do direito, que excluem exatamente a sua aplicação.

\section{Desigualdade e Aplicação da Lei}

Em relação às instituições responsáveis pela aplicação do direito, o sistema legal brasileiro poderia ser apenas formalmente considerado em acordo com os requisitos estabelecidos por nossos autores. ${ }^{13}$ A Constituição estabelece uma separação de poderes, diferenciando aqueles que produzem o direito daqueles que o aplicam. Como na grande maioria dos sistema políticos, a separação de poderes não é tão clara como aquela imaginada por Montesquieu; o Executivo possui atribuições regulamentares e adjudicativas ${ }^{14}$ o Judiciário tem autonomia administrativa para governar seus próprios assuntos, ocorrendo o mesmo com o Legislativo, que tem ampliado sensivelmente suas atribuições de fiscalização. Mas, certamente, este sistema de separação de poderes não é mais flexível do que os adotados pelos sistemas constitucionais americano, alemão e francês, paradigmáticos para nossa cultura jurídica. O Judiciário é totalmente independente e tem o poder de revisar qualquer ato da administração, inclusive a constitucionalidade de leis e até de emendas à Constituição. O sistema constitucional brasileiro também estabelece a independência do ministério público, fiscal da lei.

Assim, no papel, o sistema jurídico brasileiro também se submete à oitava "excelência" do modelo de estado de direito descrito por Fuller. No entanto, esse sistema sofre de uma epidêmica falta de congruência entre as leis estabelecidas, o comportamento dos indivíduos e a atuação dos agentes estatais responsáveis pela aplicação da lei; o que pode ser verificado pela sistemática violação de direitos humanos no Brasil ou mesmo pelas altas taxas de criminalidade em algumas regiões do país. Neste sentido, buscaremos demonstrar que o caso brasileiro é um exemplo emblemático de um sistema legal deficiente por falta de congruência na aplicação do direito.

A democratização e a adoção de uma nova Constituição não retirou muitos dos obstáculos para a implementação de um autêntico estado de direito no Brasil. A incapacidade do novo regime democrático de amenizar o problema de distribuição de riquezas no país, ${ }^{15}$ mantendo a estrutura hierárquica que permeia todo o tecido social brasileiro, impossibilita que a lei desempenhe o seu pa- pel de razão para agir pelo menos para duas parcelas da população. Muito embora o Brasil seja classificado hoje como a décima economia do globo, possui o segundo pior nível de distribuição de renda do mundo, e ocupa o 62응 posto, em termos de desenvolvimento humano, de acordo com os padrões estabelecidos pela ONU. Nesta década há um padrão em que os $10 \%$ mais ricos da população brasileira detêm cerca de $50 \%$ da riqueza nacional, enquanto os $50 \%$ mais pobres, pouco mais de $10 \%$. O investimento em educação, 3,3\% do PIB, corresponde a metade do que é aplicado nas outras 12 maiores economias do mundo, o que resulta em mais de $20 \%$ de analfabetos. Estes, entre muitos outros indicadores de drásticas desigualdades dentro da sociedade brasileira, têm um forte impacto sobre as relações de diferentes setores da sociedade com o maquinário de aplicação do direito, distorcendo a adequada realização do sistema legal. Em muitos países com esta configuração sociopolítica, os agentes públicos costumam tratar de forma "doce" as elites e de forma violenta e discriminatória os setores menos favorecidos da população. Não estamos argumentando que a desigualdade econômica seja a única razão para as distorções ocorridas no estado de direito, mas que altos níveis de desigualdade econômica e social afetam a noção de titularidade de direitos $;{ }^{16}$ dividindo a sociedade em cidadãos que são sujeitos plenos de direitos e cidadãos de segunda classe, ${ }^{17}$ aos quais o Estado não tem a obrigação de respeitar. Nosso argumento é que um patamar mínimo de igualdade é essencial para o respeito mútuo entre os indivíduos e entre estes e o Estado. Uma situação de discrepância extrema de recursos tende a criar relações hierarquizadas, e não interações cooperativas voluntárias, necessárias para se atingir um ambiente marcado pela reciprocidade.

Um dos principais problemas que afeta o estado de direito em uma sociedade com grandes disparidades na distribuição de recursos, como a brasileira, é que aqueles em pior situação econômica passam a ser vistos como uma ameaça aos que detêm a maioria dos recursos, inclusive pelos agentes responsáveis pela aplicação da lei e manutenção da ordem. Explorando a relação entre democracia e direitos humanos em países em desenvolvimento, Arat descreve um cenário no qual o hiato entre direitos civis e políticos (adquiridos após a transição) e a falta de direitos sociais e econômicos pode levar o sistema a uma crise com o aumento de descontentes, que provoca uma reação em cadeia junto às autoridades, incluindo o uso abusivo do poder coercitivo do Estado (Arat, 1995). Algumas ve- 
zes, como no Brasil, o descontentamento não é canalizado politicamente, mas é representado por um crescimento endêmico dos níveis de criminalidade,,$^{18}$ que afeta todas as esferas da sociedade, principalmente as menos favorecidas, e não apenas aquelas dotadas de mais recursos. Daí não consistir em uma luta entre classes, mas de uma luta pela sobrevivência. A resposta comum dos governos a estas classes ameaçadoras é a violência e o arbítrio. É o modo encontrado pela sociedade e pelo Estado para buscar suprimir o problema da criminalidade sem que se resolva a questão social e nem ao menos se melhore a qualidade das polícias, do ministério público e do Judiciário. Neste sentido, a falta de condições econômicas somada a altas taxas de criminalidade pode levar a uma situação de desrespeito sistemático dos direitos humanos, como a violação da integridade física, do devido processo legal e da liberdade de locomoção e, principalmente, o direito à vida, como método perverso de "pacificação" social.

Um exemplo de como o sistema legal trata os excluídos moralmente, para adotar a terminologia de Cardia, foi o massacre do Carandiru, em 1992. Apenas alguns dias após o processo de impeachment do então presidente Fernando Collor, o que foi uma das maiores demonstrações de vitalidade da sociedade civil brasileira, a polícia militar invadiu a Casa de Detenção de São Paulo para controlar uma rebelião ali iniciada. $\mathrm{O}$ resultado foi a morte de 111 presos, que estavam desarmados e não mantinham nenhum refém. Até hoje nenhuma punição foi imposta aos responsáveis pelo massacre. ${ }^{19}$ Mesmo que este tenha sido um evento extraordinário pela quantidade de pessoas mortas em um curto espaço de tempo, menos de quatro horas, o histórico da polícia brasileira mostra que o ocorrido no Carandiru foi absolutamente compatível com o comportamento da polícia em sua relação cotidiana com "suspeitos criminais" até aquele momento. ${ }^{20}$ No mesmo ano de 1992, 1.359 "suspeitos" morreram em confronto com a polícia militar do Estado de São Paulo. Embora estes números tenham caído após o Carandiru, eles continuam extremamente altos, em diversas regiões do país. No Rio de Janeiro, somente no primeiro semestre de 1998, 511 civis foram mortos pela polícia, ou seja, duas vezes mais (per capita) do que matou a polícia de São Paulo, no mesmo período. Esta prática não é apenas incentivada pela impunidade, mas também pelas próprias autoridades do governo anterior, que premiavam por bravura atos de violação de direitos humanos, como a eliminação de suspeitos (Human Right Watch, 1999). O que é sintomático aqui é que a quase totalidade dos mortos pelas polícias brasi- leiras são muito pobres e vivem na periferia social deste país. Outros exemplos de desrespeito sistemático à lei poderiam ser arrolados, como o massacre de dez trabalhadores rurais em Corumbiara, em agosto de 1995, por policiais militares de Rondônia, até o presente momento sem a punição legal dos responsáveis. A morte de 19 semterra também pela Polícia Militar em Eldorado dos Carajás, em abril de 1996, também continua impune (Amnesty International, 1998). A atuação de esquadrões da morte com a conivência dos agentes do Estado tem sido ainda responsável por milhares de mortes em todo o Brasil. No Mato Grosso do Sul, há indícios de que, somente em 1997, 129 pessoas foram mortas por matadores que agem na fronteira com o Paraguai.

A exclusão moral pode ser constatada também nos assassinatos de crianças no Brasil. Em geral, as vítimas são adolescentes do sexo masculino, entre 14 e 17 anos de idade, em sua grande maioria negros e sem histórico criminal. Trata-se basicamente de crianças pobres. Esses crimes têm, em sua maioria, autoria desconhecida; entre os de autoria conhecida os principais responsáveis são grupos de extermínio, policiais e crime organizado (Penglese, 1993). Ainda se poderia falar do trabalho forçado, que tem sido reduzido graças aos esforços do governo, mas que segundo relatório da Comissão Pastoral da Terra ainda ultrapassa $20.000 \mathrm{em}$ todo o Brasil (Human Rights Watch, 1999:106), da prostituição infantil, dos linchamentos, etc. Fenômenos que afetam os setores que detêm, em todos os aspectos, menos poder na sociedade brasileira. Neste mesmo sentido, a persistente omissão do Estado incentiva o conflito aberto entre fazendeiros e "sem-terra", que já criou um enorme número de vítimas do lado mais frágil do conflito. ${ }^{21}$

A impunidade que circunda todos estas violações é um aspecto típico de sistemas em que alguns setores detêm recursos em quantidade muito maior que os demais setores da sociedade. Também é comum em Estados fracos. As relações entre os setores que detêm mais recursos e as agências estatais encarregadas de aplicar a lei tendem a ser mais relaxadas. Privilégios são estabelecidos e corrupção e outras formas de atividades ilegais podem se tornar um modelo. Como a massa não é vista como detentora de direitos, e o Estado, teoricamente, seria representação desta massa, sua delapidação não gera qualquer conseqüência, da mesma forma que não têm consequiência as altas taxas de homicídios que afetam primordialmente a massa. A reivindicação de que este modelo também se dá em países com distribuição de renda mais eqüitativa é certamente verdadeira, porém, o senso de pri- 
vilégio, ou seja, de que se tem lei própria, não é na maioria das vezes reforçado por um alto grau de impunidade. Em países com elevados índices de concentração de riquezas, os sistemas legais tendem a ter um nível inferior de eficiência, não apenas em relação às elites, mas também àqueles criminosos que estão em melhores condições do que a massa comum dos criminosos, como traficantes de drogas, máfia e crime organizado. Neste sentido, altos níveis de impunidade encorajam o desrespeito pelo direito e a sensação de que sempre é possível se ver livre dos rigores da lei se se encontram os recursos suficientes para fazer o sistema funcionar a seu favor, frustrando, desta forma, a realização do estado de direito. Estes aspectos do caso brasileiro demonstram que a existência de um estado de direito exige que o Estado seja forte, não no sentido de violento, mas que seja capaz de impor o interesse público sobre o dos grupos privados, da presidência da República à delegacia de polícia.

Se esta análise estiver correta, as leis no Brasil não se constituem, para largas parcelas da população, em fortes razões para ação, em algo que se deva levar em conta no momento de tomada de decisão. Para aqueles "abaixo da lei”, que a gramática do sistema jurídico não incorpora, que têm seus direitos sistematicamente violados pelo Estado e pelos outros membros da sociedade, com a omissão ou conivência do Estado em punir estas violações, não há razão para se confiar na lei ou seus agentes e muito menos para levá-la em conta. Para os privilegiados, o direito também não é algo tremendamente importante para se levar em conta na hora de se praticar uma ação ou tomar uma decisão, uma vez que, normalmente, podem conquistar os seus objetivos inclusive contra o direito. ${ }^{22}$ Assim, muito embora se tenha um sistema legal que é consistente com as diversas "excelências" dos modelos de estado de direito apresentados neste artigo, a falta de um mínimo de igualdade, que é necessária para se garantir a noção de que os indivíduos são seres morais, dotados de direitos, a quem a lei e seus agentes devem tratar de forma igual, tende a inibir o surgimento de relações de reciprocidade, não hierarquizadas, e provocar uma inconsistente aplicação da lei. Assim, o estado de direito, no sentido mais amplo possível, de uma sociedade que respeita as leis, não se realiza.

\section{NOTAS}

Este artigo é dedicado a José Carlos Dias pelo seu compromisso com o Estado de Direito.
E-mail do autor: ilanud@uol.com.br

Uma primeira versão deste artigo, intitulada Reciprocity, iquality and the rule of law, foi originalmente apresentada no seminário "Legal Phylosophy" na Faculdade de Direito da Universidade de Columbia, Nova York, coordenado pelo professor Jeremy Waldron, em 1995, a quem somos gratos pela generosa leitura e pelos comentários, e posteriormente publicado na Revista do Instituto Brasileiro de Ciências Criminais, n.14, 1996.

1. Para América Latina, ver Fajnzylber (1998), Gráfico 3; para o Brasil, ver Kahn (1997).

2. Entre 1974 e 1990, mais de 30 países no sul e leste da Europa, América Latina, leste da Ásia e África transitaram de regimes autoritários ou totalitários para regimes democráticos (Huntington, 1991:3 e ss.).

3. O termo aqui não se refere a recursos financeiros, exclusivamente, mas a educação, informação, liberdade de organização, poder político, etc.

4. The road of serfdom, de 1944, e The constitution of liberty, de 1960, traduzido para o português como Os fundamentos da liberdade, 1983.

5. O conceito de lei, como ato normativo genérico e abstrato, coincide exatamente com as proposições rousseaunianas de lei: para que esta pudesse assegurar a autonomia dos cidadãos e não ser contaminada por interesses privados, ou seja, para que pudesse ser a representação fiel da vontade geral, deveria ser aplicável universalmente a todos; para uma análise do conceito de lei em Rousseau, ver Sartori (1987:382 e ss.).

6. O termo invento foi aqui utilizado no sentido que lhe empresta Carlos Nino, ao afirmar que os direitos humanos são um dos maiores "inventos" da humanidade, com isto querendo demonstrar que são um produto do engenho humano comparável às demais descobertas científicas na área da medicina, comunicações, etc. (Nino, 1989:1).

7. Neste sentido, a empreitada de Fuller é semelhante à de Rawls, que cria uma abstração em sua teoria da Justiça pela qual se pode abordar criticamente a justiça dos sistemas políticos reais, ou do próprio Contrato Social de Rousseau, e que nos permite medir o grau de conquistas democráticas de uma determinada sociedade.

8. Para Fuller, a moralidade interna do direito é uma "versão procedimental do direito natural" (Fuller, 1969:97).

9. Para Fuller, diferentemente de Hayek, o Judiciário não é necessariamente a melhor instituição para policiar o processo de aplicação do direito.

10. Por justiça natural, Raz entende um julgamento aberto, não tendencioso e dotado de outros mecanismos procedimentais que garantam a sua justiça (Raz, 1979:10).

11. Como método de legitimação dos novos regimes perante a comunidade internacional e a parcela interna da cidadania, estes países se tornam parte dos principais instrumentos internacionais de proteção da pessoa humana, que não simplesmente estabelecem uma série de direitos substantivos, mas também requerem certas instituições características do estado de direito.

12. Para uma idéia clara de mínimo social a que nos referimos, ver Waldron (1993:250 e ss.).

13. Em relação à existência de justiças militares estaduais, para julgamento de policiais militares que praticaram crimes contra civis, nem isto poderia ser dito.

14. Vale lembrar que todas podem ser revistas pelo Judiciário.

15. Grande parte dos dados quantitativos apresentados neste artigo foram retirados do artigo de Poppovic e Pinheiro (1995), com uma versão em português publicada pelo Núcleo de Estudos da Violência (1995:45 e ss.). De acordo com o último Relatório de Desenvolvimento do PNUD, o Brasil apresenta a maior disparidade na distribuição de renda entre países com mais de dez milhões de habitantes.

16. Uma análise extremamente interessante deste fenômeno de falta de titularidade de direitos por determinadas parcelas pode ser encontrada em Cardia (1995:19 e ss.). A autora desvenda, neste trabalho, o processo de "exclusão moral" a que são submetidas as camadas da sociedade que ficam à margem dos mecanismos de justiça social.

17. Usamos o termo "cidadão de segunda classe" no sentido de "underclass", pessoas destituídas de direitos, utilizado por Darhendorf (1994:14-15).

18. Para uma análise do crescimento da criminalidade ver Fajnzylber (1998) e para o Brasil, Kahn (1997).

19. Ver O Massacre do Carandiru, Human Rights Watch/America, 1992.

20. Para uma visão geral sobre violação de direitos humanos no Brasil ver relatórios preparados pelo Núcleo de Estudos da Violência da USP, de 1993 e 1995. 
21. De acordo com dados da Procuradoria Geral da República, nos últimos 20 anos mais de 1.500 trabalhadores rurais morreram por força de conflitos no campo. 22. O poder público com freqüência utiliza-se do expediente de editar atos que, embora ilegais, constituem o caminho mais curto para atingir seus objetivos imediatos; sabe que a pequena capacidade do Judiciário para processar as demandas contra estes atos dificilmente colocará em risco os seus projetos (Vieira, 1994).

\section{REFERÊNCIAS BIBLIOGRÁFICAS}

AMNESTY INTERNATIONAL. Report 1998. New York, 1998.

ARAT, Z. "Democracy and human rights in developing countries". In: POPPOVIC, M. e PINHEIRO, P.S. (orgs.). Op. cit., 1995.

CARDIA, N. "Direitos humanos e exclusão moral". Os direitos humanos no Brasil. São Paulo, Núcleo de Estudos da Violência - USP, 1995.

DARHENDORF, R. "Changing the quality of citizenship". In: The condition of citizenship. London, Bart van Steenberger ed., 1994.

DICEY, A.V. The Law of the Constitution. Indianápolis, Liberty Fund, 1982.

ELIAS, N. O processo civilizador. Rio de Janeiro, Ed. Zahar, 1993.

FAJNZYLBER, P. et alii. "What causes violent crime". World Bank Paper, 1998. FULLER, L. The morality of law. New Haven, Yale University Press, 1969.

HART, H.L. O conceito de direito. Lisboa, Fundação Calouste Gulbenkian, 1972.

HAYEK, F.A. The road of serfdom. London, 1944
The constituition of liberty. Chicago, University of Chicago, 1960.

HUMAN RIGHTS WATCH. World Report. New York, 1999.

HUNTINGTON, S. The third wave. Okalawoma, University of Okalawoma, 1991. KAHN, T. "Índice de criminalidade". Revista da Ilanud, n.2, 1997.

KELSEN, H. Teoria pura do direito. Coimbra, Armênio Amado, 1976.

NINO, C. Ética y derechos humanos. Buenos Aires, Editorial Astra, 1989, p.1.

NÚCLEO de Estudos da Violência. Relatório de Direitos Humanos. São Paulo, USP, 1995.

O’DONNELL, G. "A (in)efetividade da lei na América Latina”. Novos Estudos. São Paulo, Cebrap, n.51, 1998.

PASSUKANIS, A. Teoria geral do direito e o marxismo. Coimbra, Perpectiva Jurídica, 1977

PENGLESE, B. Justiça fatal: assassinato de crianças no Brasil pela polícia e por esquadrão da morte. Human Rights Watch/America, 1993.

POPPOVIC, M. e PINHEIRO, P.S. "How to consolidate democracy?" Human Rights Approach. Unesco, 1995.

RAZ, J. "Rule of law and its virtues". In: Liberty and the rule of law. Robert Cunningham ed., 1979.

SARTORI, G. Teoria de la democracia. Madri, Alianza Editorial, 1987.

VIEIRA, O.V. O Supremo Tribunal Federal. Jurisprudência política. São Paulo, Revista dos Tribunais, 1994.

WALDRON, J. John Rawls and the social minimum in liberal rights. Cambrigde, University Press, 1993.

WEBER, M. Economia y sociedad. México, Fondo de Cultura, 1984 